\title{
Implications of Technology and Policy for Intelligent Network Research Priorities
}

\author{
William H. Melody \\ Center for Tele-Information \\ Technical University of Denmark \\ Building $371,2^{\text {nd }} \mathrm{fl}$. \\ 2800 Lyngby, Denmark \\ Tel: +4545255174 \\ Fax: +454506 3171 \\ E-mail:melody@cti.dtu.dk
}

\begin{abstract}
Windows 95 may provide a major stimulus to Intelligent Network (IN) development, to real technological convergence between computing and telecommunication, and to a major reordering of research priorities in the field. The paper examines IN in the context of the evolution of convergence and the larger framework of information superhighway, infrastructure and society developments. It shows how the pace and direction of IN development will be driven by demand associated with organisational and institutional change, not the simple supply of greater capacity or the discovery of 'killer applications'. This will be associated with a shift in priorities to distributed networking, informationbased service development and a diversity of very specific new applications.
\end{abstract}

\section{Keywords}

Intelligent network development, convergence, information infrastructure, IN demand, IN applications.

\section{INTRODUCTION}

The launch of "Windows 95 " may turn out to be a defining moment in the evolution toward a future information society. After years of discussion about the convergence of computing and telecommunication, Windows 95 may prove to be a bridge, or the first of many bridges that begin the process of real technical convergence. Windows 95 is a major attempt to integrate telecommunication network capability into PC operating systems. As 
Windows is already on $80 \%$ of PCs, its implications for intelligent network development could be profound. Among other things, it could contribute to a major reordering of research priorities in the field. This paper examines recent developments relating to convergence in light of the economic and policy trends that are moving many countries toward an information society.

\section{PREPARING THE GROUND FOR INTELLIGENT NETWORKS}

We can now look back about a quarter century to some key policy decisions that redirected the course of development of the computing and telecommunication industries. In computing, IBM was forced by court order to unbundle its hardware and software. This fostered a rapidly growing independent software industry that passed the hardware industry in market size during the $1980 \mathrm{~s}$. Now hardware is increasingly becoming a commodity item, while software opportunities appear to have no limit.

In telecommunication, in 1968 a change in US policy forced AT\&T to permit the network attachment of terminals produced by independent suppliers. Interconnection policy and standards development became subject to the direct influence of independent equipment suppliers and large customers. It led to the general unbundling of customer terminal equipment from network services and permitted the attachment of computers to the telecommunication network. This stimulated the process of converting telecommunication equipment from analogue to digital standards, and then the gradual conversion of telecommunication networks to the digital standards of computing that is now underway.

It is widely accepted that the cornerstone of future telecommunication network design, provision, service development and applications will be new software. In keeping with the grossly exaggerated terminology adopted to describe information society developments such as 'information superhighways', 'global information infrastructures', and 'killer applications' - telecommunication software developers now claim to be creating 'intelligent networks'. As if this hyperbole isn't enough, the term 'advanced intelligent networks' already has arrived in the literature. The new communication and information networks are becoming more sophisticated and complex, requiring software development by very intelligent people. But I doubt if this adoption of the language of marketing hype will help either the research and development initiatives or public understanding.

\section{CHANGING PRIORITIES FOR RESEARCH \& DEVELOPMENT}

The history of telecommunication has been characterised by continuous improvements in technology. For many years the driving thrust of research and development was directed to conquering distance. Then the emphasis shifted to expanding capacity, and later to providing new and more diversified types of communication, such as data and video. In recent years centre stage of the telecommunication technology drama has been taken by the concept of integrating the diverse range of telecommunication services into a single network, the Integrated Services Digital Network (ISDN), with open network provision 
(ONP) expanding the ubiquity and flexibility of the network. The current popular term 'intelligent networks' apparently encompasses virtually all software development for network design, provisioning, management, service provision and applications. It covers both communication network software and computing information processing software.

But these two areas of software development have never been comfortable bedfellows. Information processing software and telecommunication software have been quite distinct historically and they remain so today. They reflect the very different heritages of the two industries and technology systems from which they have been developed. Computing has reflected a focus on information processing in a culture dominated by fierce competition, rapid improvements in technology and obsolescence of equipment, and close attention to customer demand and marketing as the primary driving force for industry development.

Telecommunication has reflected a focus on the incremental expansion of stable physical networks in a culture dominated by monopoly, technological improvement in long-lived facilities, and much closer attention to government policy than demand as the primary force driving industry development. Although there have been significant strides taken in the direction of convergence and integration over the years, the very different cultures of these two industries have kept real convergence more on the horizon than within our grasp. The attention being directed to the potential future information society by leading government policy makers in many countries has provided a stimulus toward convergence and integration, and therefore highlighted the range of problems yet to be solved on future intelligent networks.

\section{COMPONENTS OF THE INFORMATION INFRASTRUCTURE 1}

The information infrastructure of a future information society has a number of fundamental components. The telecommunication facility system, which is currently being upgraded and/or extended in all countries is the cornerstone of the infrastructure. A maximally enhanced 'broadband' telecommunication system with advanced interactive capabilities has been labelled the "information superhighway". However, the information content sector and a newly developing value-added communication services sector are equally important in the development and application of new services. The communication/information equipment sector (hardware and software) is the primary driving force behind most of the new technological developments that are opening new opportunities for both industry and individual end users. These are illustrated in figure 1.

It is apparent that the information infrastructure requires the co-ordinated development of all its components. The information superhighway is an important part of it, but only a part "the plumbing" as the Economist magazine once called it. Appropriate terminals and terminal software are essential for users to obtain access to value added services. This is where Windows 95 hopes to find a market. Ultimately, the major benefits must be found in the

\footnotetext{
${ }^{1}$ See Melody, W.,Toward a Framework for Designing Information Society Policies, CTI Working Paper No. 5 , June 1995, for a more detailed exposition and analysis of the issues summarized in this section.
} 


\section{Figure 1 - Creating the Networks for an Information Society}

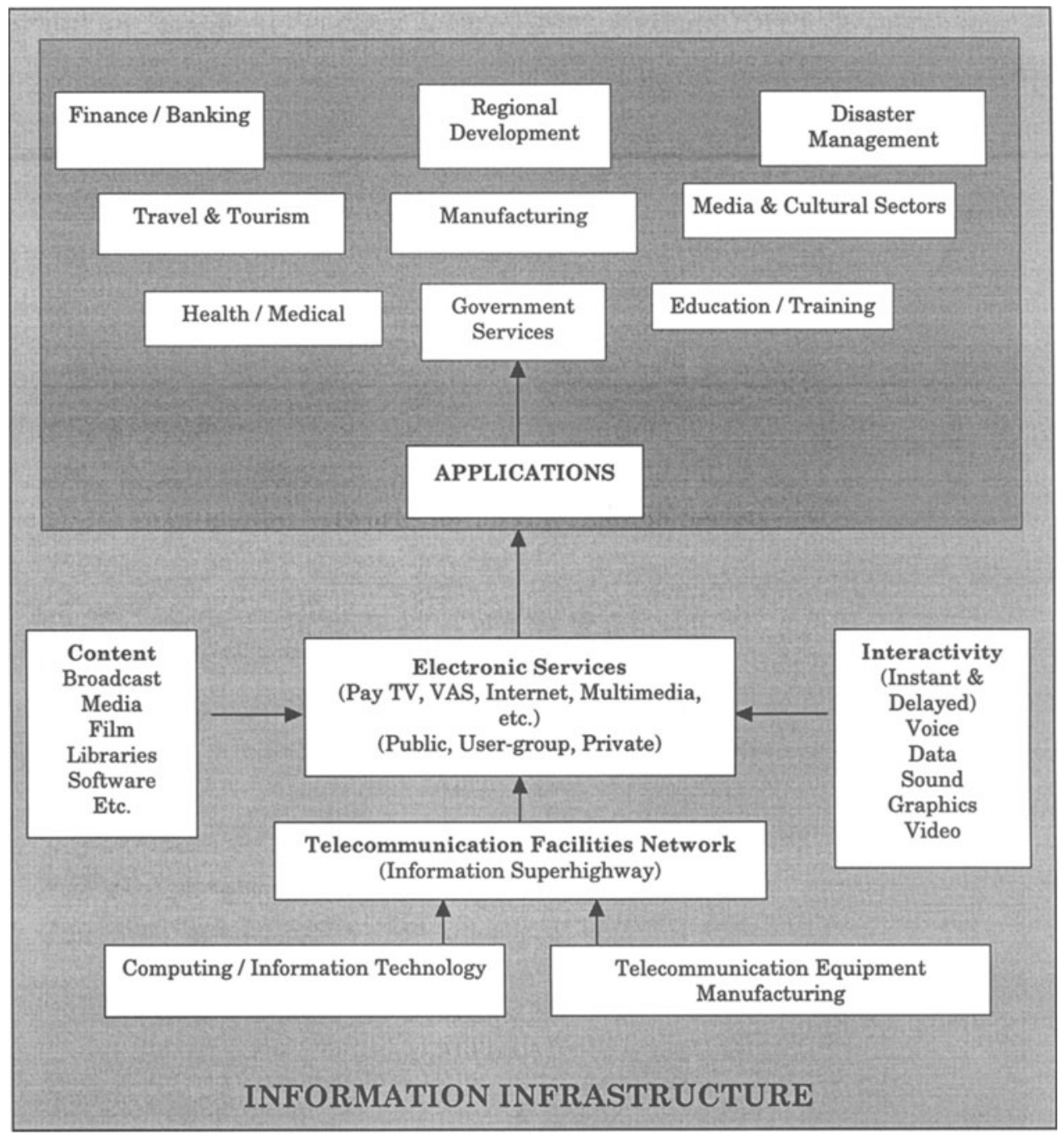


content and services. This raises a number of fundamental issues with respect to the design, management and governance of the information infrastructure, ranging from compatible technical standards development across all its components to issues of intellectual property rights, information security, privacy, universal access, pricing, monopoly and competition, etc.

A crucial element for success is the parallel development of the skill-base. New skills are needed for employment in the production sector - equipment supply, information creation and new services development. But most importantly the cultivation of user skills in the work-force attempting to apply the new services, and in potential household users will be essential to participation and market growth. The potential diffusion, of new services throughout the population will be heavily influenced by the diffusion of PCs and the skill base necessary to use them most effectively in the new environment. Achieving universal service coverage for the information infrastructure will be a difficult task, and will be achievable only over a long period of time even in countries with highly developed telecommunication systems.

The information society discussion to date has been preoccupied with the enhancement of the "Telecommunication Facilities Network" (identified in the bottom portion of Figure 1) to the standards of a broadband information superhighway. The information technology and telecommunication equipment manufacturing sectors are providing the hardware (e.g. transmission, switching, terminal equipment), and increasingly the software to the telecommunication network operators (PTTs, PTOs, Telecoms, Telcos) as well as corporate, government and individual users.

An increasing number of electronic communication and information services supplied on the telecommunication facilities network are being generated by service suppliers outside the traditional telecommunication sector, and even outside the information technology sector. This has been made possible by telecommunication reform policies which have permitted access to the network by new firms to sell value-added services (VAS) directly to customers. Figure 1 illustrates this growing separation between the telecommunication facilities network, which provides the physical capacity to communicate, and the "Electronic Services" which reflect the design of special communication services that use the facilities network. As shown in Figure 1, this includes such services as Pay TV, VAS, the Internet, Multimedia Services, and others. Electronic news services and database services are now wide-spread. The services can be public, closed user groups (e.g. the banking industry), or private (e.g. a government agency or corporate network).

The growth of electronic services as a distinct component of the information infrastructure has provided an avenue for the design of new services that are more responsive to the specific needs and demands of particular users. It reflects a shift away from the almost total supplyside orientation of service development that has characterised the traditional approach of telecom operators toward a more demand-side orientation that pays more attention to specific customer needs. These service providers typically acquire more detailed knowledge of specific customer needs, which then represents the basis of the "value-added" they 
provide. Their entry to the market also has stimulated the telecom operators to offer their own value-added services and improve their responsiveness to customer needs.

\section{APPLICATIONS OF INTELLIGENT NETWORK SERVICES}

It is doubtful that this very expensive and comprehensive upgrading of the entire electronic information infrastructure could be justified in any country simply in terms of the supply of a range of new services to business, government and household users. Although entertainment services in the form of expanded options for viewing television and playing interactive games at home are expected to provide significant markets by the 21 st century, the major benefits of the upgraded information infrastructure must arise as a result of applications of new services throughout the economy and society. These applications are expected to transform the traditional ways of operating for large and small businesses, government agencies, education and health organisations, and other institutions. It is anticipated that applications of the new electronic services will permit a major restructuring of all organisations so they can be more efficient and more responsive in their markets. The anticipated benefits will arise from the integration of the new information/communication services into the operations of each major sector of the economy, and of society. This is illustrated at the top of Figure 1.

The beginnings of such changes have been seen in the global restructuring of banking and finance, in major changes in travel and tourism, in the early applications of electronic funds transfer, just-in-time management systems, and electronic document interchange in a variety of different industries and types of organisations. It has facilitated the transformation of the music and media industries to global dimensions.

Successful applications of new services that go beyond home entertainment also will require changes in the structure of the organisations adopting them. Many large corporations are realizing that information and communication networking services justify (or require) changing their traditional hierarchical organisational structures to more horizontal structures based on distributed communication networks - providing improved management quality at reduced cost. Teleworking requires significant changes in the structure and even the culture of organisations. Similarly, self-directed education and training based upon new network services, the creation of new integrated health and medical networks, and most other potential major applications require quite fundamental institutional changes within each applications sector. The organisations applying the new services will have to be restructured so as to be able to take full advantage of the new services, and they will have to ensure the skill levels of employees, customers and suppliers are appropriate for the new structure as well as the new technologies and services.

Clearly a successful transformation of any major sector of society will have to take place over a considerable period of time. The field of education and training is a good example. The increasing requirements for "learning" in the 21 st century will mean that such activities as distance education, computer assisted learning (and eventually interactive multimedia) must be moved from the fringes of national learning systems, where they are now, to the centre. Societies will have to move the education and training system on to the electronic 
information infrastructure. But to date there has been little co-ordination, let alone convergence of policy development and planning in telecommunication and in the education/training sectors in any country.

For the future, governments in the most developed countries should not invest primarily in physical facilities for stand-alone educational institutions. Rather, investment should focus on the most efficient and effective use of a variety of new communication and information services, and new forms of content. This should permit more and more diversified opportunities for access to learning by people of all ages and circumstances. It should permit more effective use of existing educational resources. The role of teachers in this new environment would shift from being suppliers of information (filling empty vessels) to more highly valued facilitators of access to information and knowledge (guiding and collaborating in the learning activity).

The application of the full range of new electronic information and communication services is expected to permit the redesign and transformation of the education/training/learning system for the 21 st century. This will require the development of a series of intelligent networks designed to meet the very specific needs of different kinds of education in the new environment. Clearly this is a tall order and will require major reallocations of resources, both within the education/training sector and between this and other sectors, before it can be achieved. The transformation will not be an easy one and is likely to be characterized by many missteps and dislocations along the way. Figure 1 illustrates just some of the major areas of application of information infrastructure services.

\section{DIRECTIONS OF CHANGE FOR INTELLIGENT NETWORK RESEARCH PRIORITIES}

To date the research priorities for intelligent network development have been driven primarily by the public telecommunication operators and their equipment suppliers. The primary thrust has been to enhance the technical capabilities of the telecommunication system. These telecommunication sector priorities have been supported by government policy in research and development funding and other areas, particularly in Europe. A major limitation of this supply side emphasis in research has been its relative inattention to demand, and in particular its failure to uncover new demands that are necessary to justify the intelligent network enhancements now under development.

Windows 95 launches the Microsoft Network on-line service. It is expected to attract up to 3 million subscribers the first year, as many as America On-line, currently the largest service. Microsoft's goal is to make networking, and access to networking simpler and cheaper through its network, and eventually to merge it with the Internet. Whether or not this is achieved, Windows 95 has stimulated all Microsoft's current and potential information sector competitors into expanded efforts directed to ensuring Microsoft does not control key network software standards, as it has done with PC software. Developing software for improved networking is now the top priority for the computing industry. 
This industry response could signal a major shift in influence over the future direction of network development and intelligent network research priorities. This shift in influence is from the telecommunication to the information processing industries, from supply side to demand side issues, from centralised to distributed networking, and from telecommunication network enhancement to new information-based service development. It should also stimulate an increase in research associated with future service applications. In addition, it could signal a major opening of small business and residential user service opportunities, reducing the pervasive influence of the largest corporate users on telecommunication network development. As a result of Windows 95, the proportion of household PCs connected to networks can be expected to increase rapidly from its current level about $10 \%$ in the leading countries. The market for software to run PC networks is forecast at US\$ 30 billion for 1996, nearly ten times what it was in 1987.

Undoubtedly Windows 95 is as much a product of the trend of events as a cause. Perhaps the fundamental issue for the future with respect to software development is competition over the distribution of the network "intelligence" among telecommunication operators, specialist network managers, service suppliers, applications specialists in particular industry sectors and individual end users. This could represent one step in the direction of turning the telecommunication infrastructure into a commodity and forcing the public telecom operators to reassess their comparative advantages in this new market environment. For research priorities, it marks another significant step in the shift from supply to demand related issues. The telecommunication network eventually will become a great information processor with characteristics much closer to computing than to telecommunication as we know it today.

\section{REFERENCES}

Arnbak, J. (Editor). Innovative Services or Innovative Technology? IFIP/ICCC 1989, Elsevier Science Publishers B. V. (North-Holland).

Austin, Marc T. Europe's ONP bargain: What's in it for the user? Telecommunications Policy 1994, Vol. 18, Issue 2, p. 97-113.

Baker, Dan. Intelligent networks: A report from the trenches. Telephony, 1994, Vol. 227, Issue 15, p. 40-46.

Cane, Allan. Era of intelligent networks. Financial Times, London, March 1, 1995, p. VIII.

Commission of the European Communities. Recommendation of the Co-ordinated Introduction of the ISDN in the European Community. Brussels 1986, COM(86) 659 final.

Commission of the European Communities. Present Status and Future Approach for Open Access to Telecommunications Networks and Services. Brussels 1994, COM(94) 513 final. 
Commission of the European Communities. Green Paper on the Liberalisation of Telecommunications Infrastructure and Cable Television Networks. Part II. A Common Approach to the Provision of Infrastructure for Telecommunications in the European Union. Brussels 1995, COM(94) 682 final.

Commission of the European Communities. Proposal for a European Parliament and Council Directive on the Application of Open Network Provision (ONP) to Voice Telephony. Brussels 1995, COM(94) 689 final.

Downs, Stephen J. Asynchronous Transfer Mode and public broadband network: The policy opportunities. Telecommunications Policy, 1994, Vol. 18, Is. 2, p.114-136.

Higham, Nicholas. Open Network Provision in the EC: a step-by-step approach to competition. Telecommunications Policy 1993, Vol. 17, Is. 4, p. 242-249.

Melody, William H. Telecommunication: Policy Directions for the Technology and Services. Oxford Surveys in Information Technology, 1986, Vol. 3.

Melody, William H. Policy Issues in the Evolution of ISDN, in Arnbak J. (Editor), Innovative Services or Innovative Technology? IFIP/ICCC 1989, Elsevier Science Publishers B. V. (North-Holland), p. 53-62.

Melody, William H. Toward a Framework for Designing Information Society Policies. CTI Working Paper No. 5, Center For Tele-Information, Technical University of Denmark, June 1995.

Reid, A. H. The Integrated Services Digital Network: A Presentation of Related Policy Issues. Trends of Change in Telecommunications Policy, OECD, Paris, 1987, ICCP 13, p. 99-115.

\section{BIOGRAPHY}

William H. Melody is Guest Professor and Chairman of the International Advisory Board, Center for Tele-Information, Technical University of Denmark. He was Founding Director of the Centre for International Research on Communication and Information Technologies (CIRCIT), Melbourne, Australia, 1989-94; and the Programme on Information and Communication Technologies (PICT), Economic and Social Research Council, London, UK, 1985-88. He has held appointments at St. Anthony's College, Oxford University; Simon Fraser University, Vancouver; University of Pennsylvania, Philadelphia; Iowa State University, Ames, and is a former Chief Economist, US Federal Communications Commission, Washington.

He has authored five articles on communication and information technology issues in the Canadian Encyclopedia as well as the article on "Telecommunication" in the International Encyclopedia of Communications. He has been a consultant and advisor to universities, national and international government organizations, and corporations on all continents. 